\title{
Automatyzacja zgrzewania i robotyzacja spawania ościeżnic stalowych
}

\author{
Automation and robotization of welding of the steel door \\ frames
}

\section{Streszczenie}

Artykuł obejmuje opis innowacyjnego systemu do zgrzewania prądem stałym okuć do profili ościeżnic ze stali niestopowych oraz łączenie profili w gotową ościeżnicę z zastosowaniem zrobotyzowanego spawania MAG z użyciem innowacyjnej technologii Active Wire Process (AWP).

Słowa kluczowe: automatyzacja zgrzewania; robotyzacja spawania; spawanie ościeżnic

\section{Abstract}

The article includes a description of an innovative system for direct current spot welding of fittings for unalloyed steel frame profiles and for joining profiles to a finished frame with robotic MAG welding using the innovative Active Wire Process (AWP) technology.

Keywords: weld automation; robotization of welding; welding of door frames

\section{Wstęp}

W ostatnich latach obserwujemy olbrzymi boom inwestycyjny w branży budowlanej. Mówi się powszechnie, że Polska to wielki plac budowy oraz modernizacji.

Rozpędzeni deweloperzy budują domy, kamienice, bloki mieszkalne, a także setki tysięcy metrów kwadratowych powierzchni biurowej.

W tych wszystkich segmentach potrzebne są drzwi, które osadza się w ościeżnicach, a znaczący procent ościeżnic wykonuje się jako stalowe.

W dobie rosnącego poziomu konkurencji wzrasta zapotrzebowanie na nowatorskie i innowacyjne rozwiązania, zwiększające wydajność oraz produktywność przedsiębiorstw. Nie bez znaczenia jest także oczekiwanie inwestorów na zwiększenie estetyki wykonania wyrobów. Firma TECHNIKA SPAWALNICZA Poznań dla jednego $z$ wiodących producentów drzwi w Polsce opracowała i wdrożyła system do produkcji ościeżnic stalowych ze stali niestopowych.

System do produkcji ościeżnic stalowych

W skład systemu wchodzą:

1. Automat do zgrzewania elementów okuć do profili (stale niestopowe).

2. Zrobotyzowane stanowisko do spawania MAG profili ze stali niestopowych.

Efektem finalnym jest ościeżnica stalowa.

\section{Automat do zgrzewania elementów okuć do profili}

Automat jest przystosowany zamiennie do zgrzewania okuć (sześć typów) do profili, które występują w różnych kształtach i w różnych wersjach, a także jako lewe i prawe.

Okucia występują w sześciu rodzajach (kątowniki, zawieszki, kieszenie, kotwy itp.).

Przykład profilu ze zgrzanymi okuciami przedstawia rysunek 1 .

\section{Prace koncepcyjne - dobór zgrzewarki}

Koncepcja automatu do zgrzewania opracowana przez firmę TECHNIKA SPAWALNICZA i zatwierdzona przez zleceniodawcę oparta jest na wykonaniu sześciu niezależnych głowic zgrzewalniczych, zamontowanych w szeregu na konstrukcji nośnej. Taka konstrukcja stanowiska powoduje, że odległości poszczególnych głowic od źródła zasilania - transformatora, jest różna i maksymalnie wynosi ok. 1500 mm i pod tym kątem analizowano dobór odpowiedniej zgrzewarki. Obecnie produkowane są trzy podstawowe typy zgrzewarek, różniące się ceną i możliwościami technicznymi.

1. Zgrzewarki prądu przemiennego (400 V, najtańsze).

2. Zgrzewarki trójfazowe prądu stałego.

3. Zgrzewarki inwertorowe z wewnętrzną przemianą częstotliwości (najdroższe).

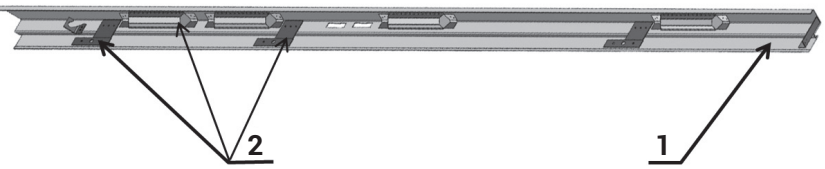

Rys. 1. Przykład profilu ze zgrzanymi okuciami Fig. 1. Example of a profile with welded fittings

Inż. Mirosław Nowak, mgr inż. Mariusz Nowicki - TECHNIKA SPAWALNICZA

Autor korespondencyjny/Corresponding author. miroslaw.nowak@techspaw.com.pl 
W tablicy I [1] podano przykładowe wartości prądu zgrzewania wymaganego $w$ obwodzie wtórnym zgrzewania, a na rysunku 3 [1] przedstawiona jest zależność średnicy jądra zgrzeiny od natężenia prądu zgrzewania dla trzech wymienionych typów zgrzewarek.

Z tablicy I i rysunku 2 wynikają zalety bądź wady różnego typu zgrzewarek.

W tej sytuacji ze względu na zjawisko dużego spadku wartości prądu zgrzewania wraz ze zwiększaniem odległości pomiędzy transformatorem a punktem zgrzewania, zastosowanie transformatora prądu przemiennego, wymagałoby użycia bardzo dużej jednostki kompensującej straty. Jednak duży transformator prądu przemiennego obciąża nierównomiernie sieć zasilającą (tylko dwie fazy) i wymaga

Tablica I. Przykładowe wartości prądu zgrzewania wymaganego w obwodzie wtórnym obu zgrzewarek

Table I. Examples of welding current values required in the secondary circuit of both welders

\begin{tabular}{|c|c|c|c|c|}
\hline $\begin{array}{c}\text { Rodzaj } \\
\text { prądu } \\
\text { zgrzewania }\end{array}$ & $\begin{array}{c}\text { Natężenie } \\
\text { prądu } \\
\text { zgrzewania }\end{array}$ & $\begin{array}{c}\text { Napięcie } \\
\text { wtórne, } \\
\text { V }\end{array}$ & $\begin{array}{c}\text { Pierwotny } \\
\text { prąd fazo- } \\
\text { wy, A }\end{array}$ & $\begin{array}{c}\text { Moc transfor- } \\
\text { matora ener- } \\
\text { getycznego, \% }\end{array}$ \\
\hline $50 \mathrm{~Hz}$ & 40 & 11,9 & 1250 & 422 \\
\hline Prąd stały & 40 & 4,0 & 296 & 100 \\
\hline
\end{tabular}

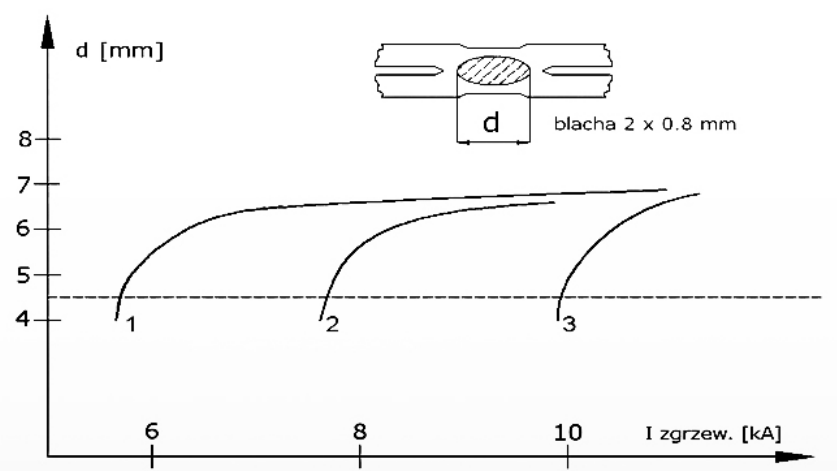

Rys. 2. Zależność średnicy jądra zgrzeiny od natężenia prądu zgrzewania przy stosowaniu zgrzewarek: inwertorowej (poz. 1), prądu stałego (poz. 2) i prądu przemiennego $400 \mathrm{~V}$ (poz. 3)

Fig. 2. The dependence of the weld core diameter on the welding current intensity when using welding machines: inverter (pos. 1), direct current (pos. 2) and alternating current $400 \mathrm{~V}$ (pos. 3) zastosowania znacznie większych przekrojów przewodów zasilających oraz zabezpieczeń sieci.

Ewentualne użycie sześciu transformatorów prądu przemiennego (każdy przy kolejnej głowicy) powoduje problemy konstrukcyjne, ale również jest nieekonomiczne (sześć transformatorów, sześć sterowników itd.) i generuje wysokie koszty wykonania. Dlatego wzięto pod uwagę zastosowanie droższego pojedynczego transformatora prądu stałego o mocy 100 kVA, który jest w minimalnym stopniu wrażliwy, jeżeli chodzi o zmianę parametru prądu zgrzewania w zależności od odległości pomiędzy miejscem zgrzewania a źródłem. Wybór transformatora prądu stałego skutkuje również redukcją jego mocy oraz równomiernym rozkładem obciążenia sieci zasilającej (3 x 400 V). Proces zgrzewania realizowany przy zastosowaniu prądu stałego umożliwia uzyskanie takich samych zgrzein przy użyciu prądów zgrzewania o ok. $20 \%$ mniejszych niż w przypadku prądu przemiennego [2], daje to zauważalne oszczędności przy poborze prądu w obwodzie pierwotnym (rys. 2) [1].

Mniejszy prąd wtórny przy tym samym efekcie zgrzewania skutkuje mniejszym zużyciem elektrod, które pracują pod mniejszym obciążeniem prądowym.

Podczas doboru transformatora rozpatrywane było zastosowanie transformatora inwertorowego, ale uznano, że w przypadku produkcji, gdzie stosowane są materiały jednorodne, a zgrzewanie jest garbowe (czasy powyżej 100 ms, prądy powyżej $8 \mathrm{kA}$ ), niepotrzebne jest stosowanie tak precyzyjnego, a jednocześnie o ok. $20 \%$ droższego, źródła zasilania jakim jest inwerter.

\section{Budowa automatu do zgrzewania profili z okuciami}

Głównymi zespołami automatu (rys. 3) są:

- Zgrzewarka specjalna prądu stałego wyposażona w jeden transformator o mocy 100 KVA i sześć głowic zgrzewalniczych (firmy TECNA) (poz. 1).

- Sześć przyrządów (poz. 2) do mocowania odpowiednich okuć (poz. 2a) przytwierdzonych do głowic zgrzewalniczych z możliwością regulacji $w$ zależności od wersji zgrzewanego profilu.

- Sześć siłowników zgrzewalniczych (poz. 3) o sile docisku do 1242 daN każdy.

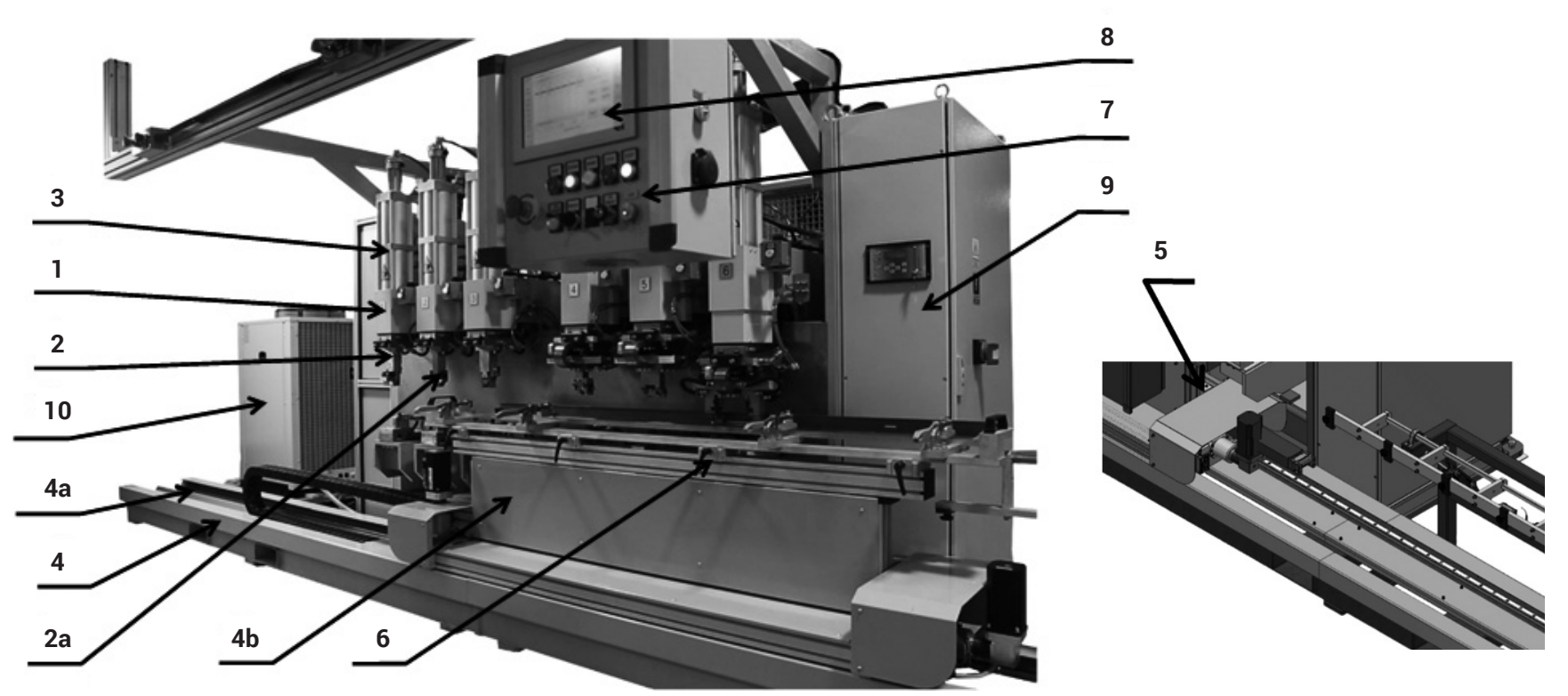

Rys. 3. Automat do zgrzewania profili z okuciami

Fig. 3. Automatic welding machine for profiles with fittings 
- Specjalny tor jezdny (poz. 4) z przesuwem wzdłużnym (poz. 4a) i przesuwem poprzecznym (poz. 4b). Oba przesuwy napędzane są serwonapędami.

- Wózek jezdny napędzany serwonapędem (poz. 5). Wózek jezdny przytwierdzony jest do modułu przesuwu poprzecznego.

- Uniwersalny przyrząd (poz. 6) do ręcznego zaciskania profili przytwierdzony do wózka jezdnego.

- Układ sterowania (poz. 7) z panelem HMI (ang. Human Machine Interface), (poz. 8). HMI posiada kilkadziesiąt okien, a między innymi: ekran główny (rys. 4), ekran sterowania ręcznego, ekran receptury, ekran serwisowy, ekran diagnostyki.

- Szafa logiki (poz. 9).

- Agregat chłodzący (poz. 10)

Ponadto, automat obudowany jest stalowymi ściankami ochronnymi. Wejście do automatu zabezpieczone jest kurtynami świetlnymi. Automat spełnia wymogi CE.

Cykl pracy zgrzewarki jest następujący:

- operator wybiera na pulpicie dotykowym wersję profilu oraz jego długość;

- stanowisko automatycznie przystosowuje się do wykonywania określonych ilości ruchów oraz sukcesywnego i prawidłowego zwalniania dostępu dla pracownika do kolejnych głowic zgrzewalniczych podczas procesu wykonywania kompletnego profilu lewego lub prawego;

- operator zakłada wybrany profil w uniwersalnym przyrządzie (poz. 6);

- przy każdej głowicy (poz. 1), która bierze udział w zgrzewaniu, pulsujący przycisk sygnalizuje, że należy w danej głowicy umieścić odpowiednie okucie;

- operator zakłada kolejne okucia do odpowiednich przyrządów (poz. 6) (maksymalnie sześć) i kasuje przyciskiem pulsowanie białej lampki - detal przygotowany jest do zgrzewania;

- po wyjściu poza obszar chroniony barierą optyczną, pracownik uruchamia przyciskiem start cyklu (poz. 5);

- wózek z założonym profilem podjeżdża w zadanej kolejności pod kolejne głowice i następuje zgrzewanie garbowe okuć do profilu;

- po zgrzaniu wszystkich założonych na automacie okuć zaczynają pulsować przyciski informując operatora gdzie jeszcze należy umieścić kolejne okucia (na niektórych profilach występują te same okucia kilkakrotnie);

- operator tak długo uzupełnia okucia aż żadna lampka nie pulsuje po zakończeniu kolejnego cyklu zgrzewania, co oznacza, że profil jest gotowy, a wózek z profilem odjeżdża na pozycję wyładunku.

Orientacyjne parametry zgrzewania garbowego okucia posiadają w zależności od typu 2 do 6 garbów. W zależności od grubości blach okuć (od 0,8 do $2 \mathrm{~mm}$ ) osiągnięto zamierzony efekt zgrzewania przy sile docisku od 120 do 350 daN, ilości cykli 5 do 8 i natężeniu prądu zgrzewania 5 do 15 kA.

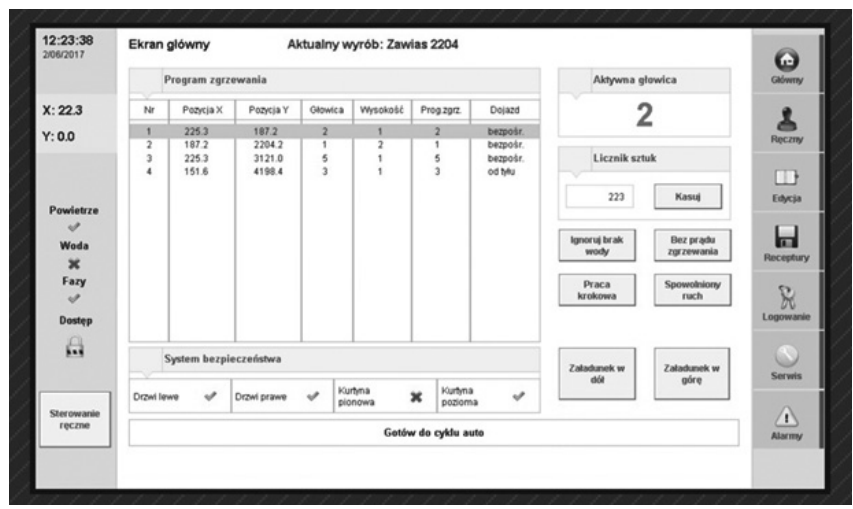

Rys. 4. Ekran główny HMI

Fig. 4. HMI main screen

\section{Stanowisko zrobotyzowane do spawania metodą MAG ościeżnic stalowych}

Każda ościeżnica (rys. 5) składa się z profilu lewego (poz. 1) i prawego (poz. 2), do których zgrzane zostały we wcześniejszym procesie okucia oraz z profilu środkowego (łącznika) (poz. 3).

Z uwagi na skomplikowany kształt profili - spoina ciągła, składająca się z krótkich odcinków, a także niewielką grubość profili (1,5 mm), zastosowano robot TAWERS firmy PANASONIC z innowacyjną technologią spawania AWP (ang. Active Wire Proces).

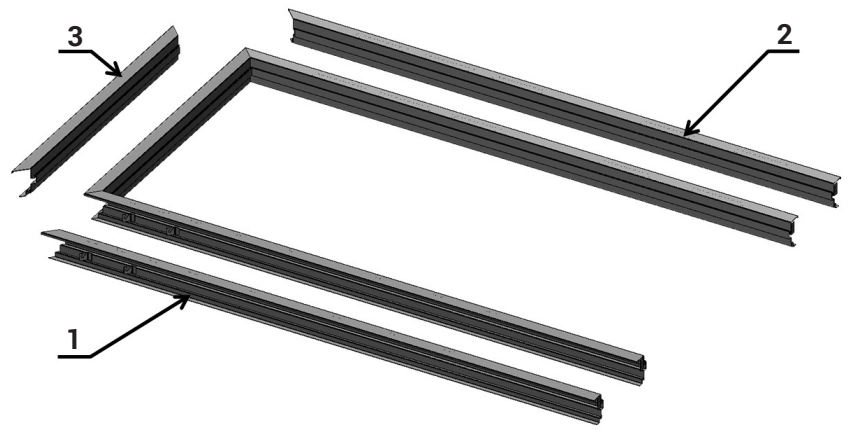

Rys. 5. Budowa ościeżnicy

Fig. 5. Construction of the door frame

Na system TAWERS ACTIVE WIRE składa się standardowy system TAWERS MAG, uchwyt spawalniczy Servo Pull (rys. 6) z aktywnym podawaniem drutu, jednostka Wire Booster (rys. 8) oraz oprogramowanie ACTIVE WIRE [3].

TAWERS ACTIVE WIRE umożliwia spawanie stali drutem litym oraz drutem proszkowym o średnicy $0,8 \div 1,2 \mathrm{~mm}$ prądem do 350 A w cyklu P60\%. Najlepsze rezultaty uzyskuje się w zakresie prądowym do $200 \mathrm{~A}$. Ideą układu jest uchwyt spawalniczy Servo Pull, który powtarza z dużą częstotliwością ruch wysuwania i cofania drutu, zapewniając stały krótki cykl łuku spawalniczego, co ogranicza ilość odprysków (rys. 7). Bardzo istotną częścią całego systemu jest urządzenie Wire Booster (rys. 8) do wspomagania podawania drutu.

Urządzenie jest montowane bezpośrednio na beczce $z$ drutem lub na kasecie szpuli z drutem, gdzie przez prowadnik spiralny doprowadza płynnie drut do uchwytu spawalniczego [3].

Metoda AWP dzięki aktywnemu podawaniu drutu umożliwia osiągnięcie krótkiego cyklu łuku, co pozwala na spawanie

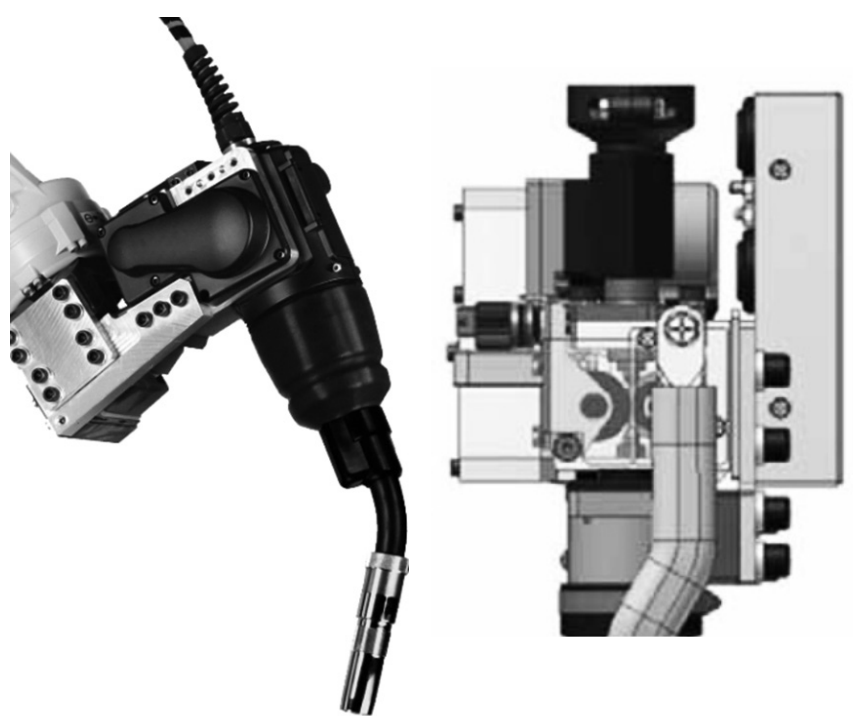

Rys. 6. Uchwyt Servo Pull

Fig. 6. Servo Pull grip 
Standardowa metoda MAG

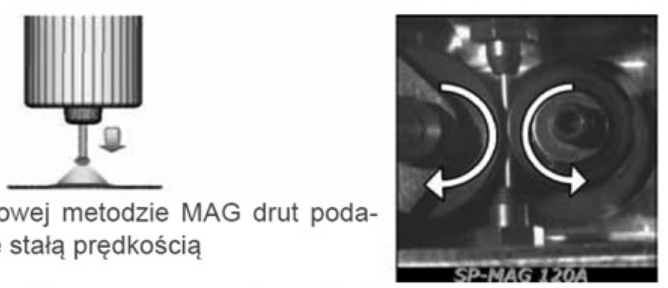

Aktywny proces podawania drudtu AWP

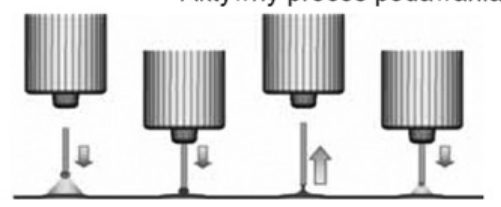

Drut do spawania powtarza ruch wysuwania i cofania zapewniając stały krótki cykl łuku spawalniczego, co ogranicza ilość odprysków.

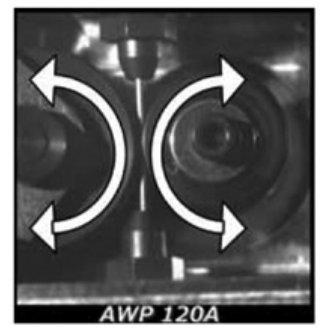

Rys. 7. Porównanie metody MAG i systemu AWP

Fig. 7. Comparison of MAG and AWP system

materiału ulegającego naprężeniom przy jednoczesnym zachowaniu wysokiej jakości spoin i ograniczeniu ilości powstających odprysków.

Dzięki AWP występuje nie tylko mniej odprysków, ale powstające odpryski są drobniejsze o mniejszej objętości, co zapobiega ich przyklejaniu się do spawanych elementów [3].

Metoda AWP dzięki aktywnemu podawaniu drutu zmniejsza odkształcenia i naprężenia spawalnicze. Ograniczenie ilości odprysków jest możliwe dzięki kontroli sekwencji odrywania kropli płynnego metalu oraz gwałtowne obniżenie wartości prądu wyjściowego. Stabilizacja łuku przez ciągłą zmianę prędkości podawania drutu zapobiega nieregularnemu skracaniu drutu, co w przeciwnym wypadku prowadzi do generacji odprysków [3].

Przykładowe parametry spawania, które pozwoliły na wykonanie ościeżnicy o grubości profilu $0,8 \mathrm{~mm}$ w klasie $B$ to: natężenie prądu $90 \mathrm{~A}$, napięcie $16,5 \mathrm{~V}$, prędkość spawania $0,6 \mathrm{~m} / \mathrm{min}$.

\section{Budowa stanowiska do zrobotyzowanego spawania MAG}

Stanowisko (rys. 9) posiada dwie stacje robocze A i B z usytuowanym w środku robotem TA-1400 WG3 Tawers (Panasonic) (poz.1). Robot jest zintegrowany ze źródłem wytwarzającym prąd spawania (350 A przy pracy P60\%) (poz. 2) wyposażonym w system Active Wire Proces. Widoczny na rysunku 9b pakiet hybrydowy wykonany jest w ten sposób, że za wyjątkiem prowadnika drutu, który jest prowadzony na zewnątrz, wszystkie przewody prowadzone są wewnątrz robota. Takie rozwiązanie umożliwia płynne podawanie drutu nawet przy niekorzystnym ustawieniu ramienia robota. W obu stacjach zainstalowane są pozycjonery Pana Dice 500 (Panasonic) (poz. 3), a po drugiej stronie umieszczone są słupki podporowe z ułożyskowaniem (poz. 4). Na ramach nośnych (poz. 5) zainstalowane są przyrządy uniwersalne (poz. 6) z możliwością przezbrojenia na dany typ ościeżnicy. Profile (poz. 7) są zaciskane ręcznie w przyrządach. Stacje A i B rozdzielone są pneumatycznie rozsuwanymi kurtynami (zaciemnienie 9 DIN) (poz. 8), które chronią wzrok operatora. System z trzech stron obudowany jest ściankami stalowymi (poz. 9), a wejścia do stacji A i B zabezpieczone

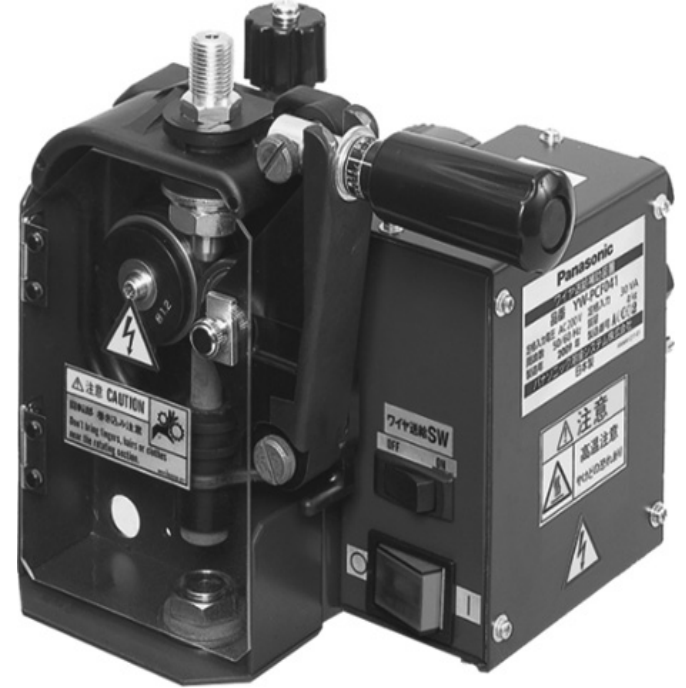

Rys. 8. Wire Booster

Fig. 8. Wire Booster

są kurtynami świetlnymi (poz. 10). Ponadto, na rysunku 9 zaznaczono stację czyszczenia palnika (poz. 11) i szafę logiki (poz.12) z widocznym panelem sterującym (poz. 13). System posiada znak CE.
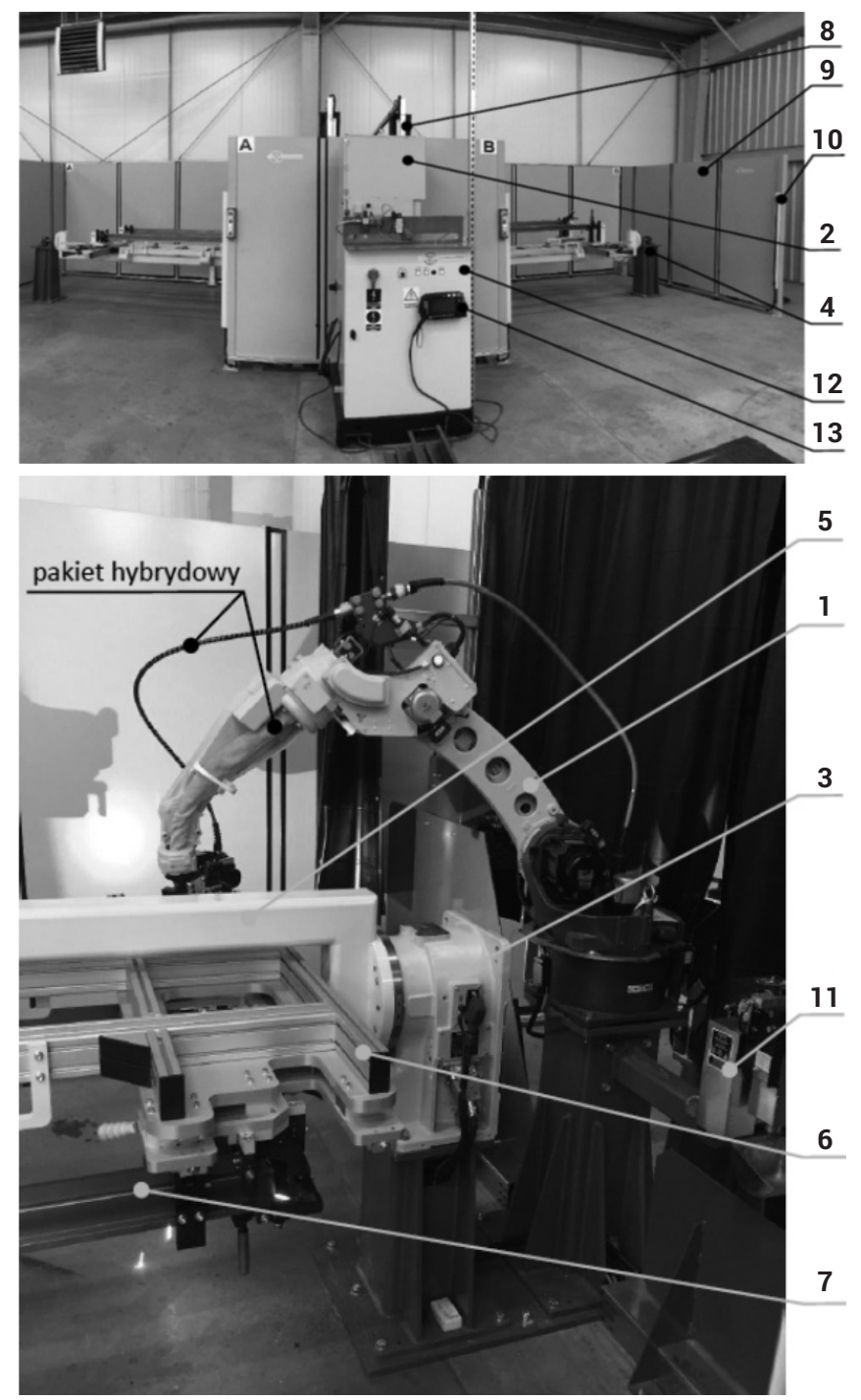

Rys. 9. Budowa stanowiska zrobotyzowanego

Fig. 9. Construction of a robotic stand 


\section{Wnioski}

1. Omówiony system przyczynił się do wzrostu wydajności i produktywności zarówno w procesie zgrzewania, jak i w procesie spawania.

2. Dzięki wdrożeniu automatu do zgrzewania i zastąpieniu spawania półautomatycznym spawaniem zrobotyzowanym firma wzmocniła swoją konkurencyjność na rynku krajowym i europejskim.

3. Niniejsze wdrożenie wzmocniło postrzeganie zleceniodawcy, jako bardzo innowacyjnego.

\section{Literatura}

[1] Piątek M.: Urządzenia stosowane w procesie zgrzewania rezystancyjnego: Zgrzewanie $\mathrm{Nr}$ 1, 1, 2002.

[2] Nowak M., Nowicki M.: Kierunki rozwoju technik i technologii zgrzewania na przykładzie rozwiązań firmy TECNA, Przegląd Spawalnictwa nr 11, 2011.

[3] Nowak M., Wiśniewski D., Buchowski J., Jędrzejak K.: Innowacje technologiczne firmy PANASONIC w zrobotyzowanym spawaniu Cieńskich elementów metalowych na przykładzie wdrożeń firmy TECHNIKA SPAWALNICZA. 